\title{
Progranulin modulates cholangiocarcinoma cell proliferation, apoptosis, and motility via the $\mathrm{PI3K} / \mathrm{pAkt}$ pathway
}

This article was published in the following Dove Press journal:

OncoTargets and Therapy

\author{
Minerva Daya ${ }^{1-3}$ \\ Watcharin Loilome ${ }^{1,3}$ \\ Anchalee Techasen ${ }^{3,4}$ \\ Malinee Thanee ${ }^{3}$ \\ Prakasit Sa-Ngiamwibool ${ }^{4,5}$ \\ Attapol Titapun ${ }^{5,6}$ \\ Puangrat Yongvanit ${ }^{3}$ \\ Nisana Namwat ${ }^{1,3}$ \\ 'Department of Biochemistry, \\ Faculty of Medicine, Khon Kaen \\ University, Khon Kaen, Thailand; \\ ${ }^{2}$ Department of Biochemistry, Faculty \\ of Pharmacy, University of Santo \\ Tomas, Sampaloc, Manila, Philippines; \\ ${ }^{3}$ Cholangiocarcinoma Research \\ Institute, ${ }^{4}$ Faculty of Associated \\ Medical Science, ${ }^{5}$ Department of \\ Pathology, ${ }^{6}$ Department of Surgery, \\ Faculty of Medicine, Khon Kaen \\ University, Khon Kaen, Thailand
}

Correspondence: Nisana Namwat Department of Biochemistry, Faculty of Medicine, Khon Kaen University, 123 Mittraphap Road, Khon Kaen 40002, Thailand

Tel/fax +6643348386

Email nisana@kku.ac.th

\begin{abstract}
Progranulin (PGRN) is a growth factor normally expressed in rapidly cycling epithelial cells for growth, differentiation, and motility. Several studies have shown the association of PGRN overexpression with the progression of numerous malignancies, including cholangiocarcinoma (CCA). However, the underlying mechanisms on how PGRN modulates CCA cell proliferation and motility is not clear. In this study, we investigated the prognostic significance of PGRN expression in human CCA tissue and the mechanisms of PGRN modulation of CCA cell proliferation and motility. We found that CCA tissues with high PGRN expression were correlated with poor prognosis and likelihood of metastasis. PGRN knockdown KKU-100 and KKU-213 cells demonstrated a reduced rate of proliferation and colony formation and decreased levels of phosphatidyl inositol-3-kinase (PI3K) and phosphorylated Akt (pAkt) proteins. Accumulation of cells at the G1 phase was observed and was accompanied by a reduction of cyclin D1 and CDK4 protein levels. Knockdown cells also induced apoptosis by increasing the Bax-to-Bcl-2 ratio. Increased cell apoptosis was confirmed by annexin V-FITC/PI staining. Moreover, suppression of PGRN reduced CCA cell migration and invasion in vitro. Investigating the biomarkers in epithelial-mesenchymal transition (EMT) revealed a decrease in the expression of vimentin, snail, and metalloproteinase-9. In conclusion, our findings imply that PGRN modulates cell proliferation by dysregulating the G1 phase, inhibiting apoptosis, and that it plays a role in the EMT affecting CCA cell motility, possibly via the $\mathrm{PI} 3 \mathrm{~K} / \mathrm{pAkt}$ pathway.
\end{abstract}

Keywords: progranulin, cholangiocarcinoma, proliferation, migration, invasion, EMT

\section{Introduction}

Cholangiocarcinoma (CCA) is a cancer arising from the epithelial cells lining bile ducts, and its prevalence is increasing worldwide. ${ }^{1}$ In Thailand, CCA is the major public health problem, particularly in the Northeast Thailand where the etiology of the disease is strongly associated with liver fluke (Opisthorchis viverrini) infection. Infected individuals develop a persistent bile duct inflammation that can progress to CCA. ${ }^{2}$ The incidence rates of CCA in this region are $\sim 93-318$ per 100,000 people per year, affecting males more than females, with an estimated 20,000 deaths per year..$^{3,4}$ The differences in the development of CCA between genders have been previously investigated in experimental animal infected with $O$. viverrini. These results showed no gender differences in individual's responses to the infection and in the development of CCA, an implication that the higher prevalence of opisthorchiasis among males than that in females may depend on individual exposure to risk factors rather than gender difference. ${ }^{5}$ Tobacco smoking and alcohol consumption are among 
the risk factors associated with the production of free radical intermediates causing several types of DNA lesions leading to the development of cancer. ${ }^{6}$ Although habitual smoking and heavy alcohol consumption are more common among males in the region, there is no clear evidence for gender differences that associate smoking and drinking in the progression of CCA. ${ }^{7,8}$ Study on gender differences remains a challenge, elucidating the differences in hormonal expressions could possibly provide better understanding on gender differences in opisthorchiasis and the development of CCA..$^{9-11}$ CCA progression is relatively slow, and patients present at the hospital mostly with late-stage disease when the cancer has metastasized to other organs. Chemotherapy in combination with surgery, rather than surgery alone, can reduce the tumor size and prolong the patients' survival. ${ }^{12}$ Therefore, the underlying mechanisms promoting tumor cell function, particularly the changes in molecular pathways during CCA progression, need to be investigated. This will contribute to the improvement of CCA treatment guidelines.

Progranulin (PGRN) is a secreted cysteine-rich glycoprotein growth factor that is involved in inflammation and wound response. It is also an important mediator of tumor cell functions. It is expressed not only in rapidly cycling epithelial cells but also in leukocytes, neurons, and chondrocytes. ${ }^{13}$ Overexpression of PGRN has been observed in numerous tumors of epithelial origin, including breast, ovary, prostate, renal, liver, and bile duct cancers. ${ }^{14,15}$ These tumors show a strong correlation among high PGRN expression, a poor prognosis, and tumor severity. PGRN mediates tumor cell functions by regulating the rate of epithelial cell division and promotes the transformation to an invasive phenotype of these cells. PGRN activates oncogenic signaling pathways such as the extracellular-regulated kinase (ERK), mitogenactivated protein kinase (MAPK), phosphatidyl inositol-3kinase (PI3K), and focal adhesion kinase (FAK). ${ }^{15}$

Activation of PI3K/Akt pathway is commonly observed in tumors overexpressing PGRN. The downstream effectors of the Akt pathway induce the cells to proliferate and transform into the metastatic phenotype..$^{15-18}$ The epithelialmesenchymal transition (EMT) is recognized as an important event in tumor metastasis in which the epithelial cells lose their apicobasal polarity, leading to reduced cell-cell adhesions and the acquisition of mesenchymal invasive characteristics. ${ }^{19}$ The Akt pathway promoting EMT in tumors confers the motility required for invasion and metastasis. Moreover, EMT is induced by various cytokines and growth factors. ${ }^{20}$ Among the growth factors associated with tumor metastasis, the possible involvement of PGRN in the EMT has not been previously addressed.

Persistent inflammation in the biliary tract strongly predisposes individuals to the development of CCA. ${ }^{3}$ The inflammatory cytokine, interleukin-6 (IL-6), is upregulated in CCA, which drives the overexpression of PGRN mediating cell proliferation by inactivating the forkhead box protein $\mathrm{O} 1$ (FoxO1), a downstream target of Akt signaling. ${ }^{18}$ Other molecular changes underlying PGRN-induced cell proliferation need further investigation to provide a better understanding of the role of PGRN in the progression of CCA.

In this study, we demonstrated the prognostic significance of PGRN expression and the changes in the molecular pathway underlying the involvement of PGRN in CCA cell proliferation, migration, and metastasis.

\section{Materials and methods Clinical samples}

CCA tissues were collected from 50 patients admitted at Srinagarind Hospital, Khon Kaen University (Khon Kaen, Thailand) from January 2004 to December 2010. Of the 50 CCA patients investigated, $72 \%$ were male and $28 \%$ were female, resulting in a male-to-female ratio of 2.6:1. The age of patients ranged from 39 to 74 years (mean \pm SD, $59 \pm 7.7$ years). The patients were at an advanced stage of the disease with $48 \%$ presenting with metastases. In this study, the histological types were classified as papillary type CCA (50\%) and non-papillary type CCA (50\%). The protocols for the collection of tissues and the study were approved by the Ethics Committee for Human Research, Khon Kaen University (no HE571283), and written informed consent was provided by all patients. The 50 CCA formalin-fixed, paraffin-embedded tissues stored at the specimen bank of the Liver Fluke and Cholangiocarcinoma Research Center (Faculty of Medicine, Khon Kaen University, Khon Kaen, Thailand) were cut into $4-\mu \mathrm{m}$-thick sections.

\section{CCA cell lines and cell cultivation}

The human CCA cell lines KKU-100 and KKU-213 were obtained from the Japanese Collection of Research Bioresources (JCRB) Cell Bank. The human cholangiocyte MMNK1 cell line (transduced with SV40T and hTERT) ${ }^{21}$ was a gift from Professor Naoya Kobayashi (Okayama University, Japan). Cells were cultured in HAM-F12 (Thermo Fisher Scientific, Waltham, MA, USA) supplemented with $10 \%$ heat-inactivated fetal bovine serum (FBS), $100 \mathrm{U} / \mathrm{mL}$ penicillin, and $100 \mathrm{mg} / \mathrm{mL}$ streptomycin (Thermo Fisher Scientific) at $37^{\circ} \mathrm{C}$ with $5 \% \mathrm{CO}_{2}$. 


\section{Immunohistochemical (IHC) staining of CCA tissues}

The tissue sections $(4 \mu \mathrm{m})$ of formalin-fixed, paraffinembedded samples were deparaffinized in xylene and rehydrated in a series of graded alcohol solutions. Antigen retrieval was performed in $10 \mathrm{mM}$ citrate buffer $(\mathrm{pH} 6.0)$ at high power for $10 \mathrm{~min}$ using a microwave oven. Then, the sections were incubated with $0.3 \%(\mathrm{v} / \mathrm{v})$ hydrogen peroxide $\left(\mathrm{H}_{2} \mathrm{O}_{2}\right)$ in phosphate-buffered saline (PBS) for $1 \mathrm{~h}$, and nonspecific bindings were blocked with $10 \%(\mathrm{w} / \mathrm{v})$ skimmed milk in PBS for $1 \mathrm{~h}$. The tissue sections were incubated with mouse monoclonal anti-human PGRN (1:50; Cat no PG359-7; Adipogen Inc., Yeonsu-gu, Incheon, South Korea) in a humidified chamber overnight at $4^{\circ} \mathrm{C}$. The following day, the sections were washed with $0.1 \%(\mathrm{v} / \mathrm{v})$ Tween 20 in PBS and were incubated with peroxidase-conjugated Envision ${ }^{\mathrm{TM}}$ (Agilent Technologies, Santa Clara, CA, USA) for $1 \mathrm{~h}$. The immunostaining was developed with a 3,3'-diaminobenzidine tetrahydrochloride (DAB) substrate kit (Vector Laboratories, Burlingame, CA, USA) for 5 min and then counterstained with Mayer's hematoxylin. The sections were dehydrated stepwise in increasing ethanol concentrations, cleared with xylene, and finally mounted with permount. The stained sections were viewed under a light microscope. The staining frequency of these proteins was semiquantitatively scored based on the percentage of positive cells as follows: $0 \%=$ negative, $1 \%-25 \%=+1,26 \%-50 \%=+2$, or $>50 \%=+3$. The staining intensity in the tumor cells was scored as negative $=0$, weak $=1$, moderate $=2$, or strong $=3$. Qualitative expression patterns were calculated by multiplying the frequency score with the intensity score and classified into three categories: negative; 1-3, low expression; or 4-9, high expression.

\section{Transient knockdown of PGRN expression}

The small interfering RNAs (siRNAs) of human PGRN and control siRNA were purchased from Dharmacon (GE Healthcare Bio-Sciences Corp., Piscataway, NJ, USA). Briefly, $9.0 \times 10^{4}$ cells were cultured in a six-well plate, and the cells were transfected with a final concentration of $50 \mathrm{nM}$ of siRNA duplexes using Lipofectamine transfection reagent (Thermo Fisher Scientific). Then, transfected cells were incubated at $37^{\circ} \mathrm{C}$ in $5 \% \mathrm{CO}_{2}$ for $48 \mathrm{~h}$. Silencing of PGRN expression was confirmed with Western blot analysis.

\section{Western blot analysis}

Transfected cells were lysed using radioimmunoprecipitation assay (RIPA) buffer containing protease K inhibitor cocktail,
$1 \%$ NP-40, $0.5 \%$ sodium deoxycholate, $0.1 \%$ sodium dodecyl sulfate, and deionized water (Thermo Fisher Scientific), and the total proteins were extracted by centrifugation. The extracted proteins were measured using the bicinchoninic acid assay (Thermo Fisher Scientific). Equal amounts of extracts were separated by sodium dodecyl sulfate polyacrylamide gel electrophoresis (SDS-PAGE) and transferred onto a polyvinylidene fluoride (PVDF) membrane (EMD Millipore, Billerica, MA, USA). The membrane was blocked with 5\% skimmed milk in PBS with 0.5\% Tween-20 (PBST) or trisbuffered saline (TBS) and incubated with the appropriate antibody. The following primary antibodies were used: mouse monoclonal anti-PGRN (1:3,000, Adipogen Inc.), anti-PI3K (1:2,000, Cat no 611342; BD Biosciences, San Diego, CA, USA), anti-phosphorylated Akt (pAkt) (ser473) (1:1,000, Cat no 560397; BD Biosciences), anti-CDK4 (DCS156) (1:500, Cat no 2906; Cell Signaling Technology Inc., Danvers, MA, USA), anti-vimentin (1;1,000, Cat no ab92457; Abcam, Cambridge, England, UK), anti-Bax (1:1,000, Cat no 810983, BD Biosciences), rabbit polyclonal anti-cyclin D1 (1:500, Cat no 29225; Cell Signaling Technology Inc.), anti-Bcl-2 (1:1,000, Cat no 2876; Cell Signaling Technology Inc.), anti-snail (1:100, Cat no 82846; Abcam), and goat polyclonal anti-human metalloproteinase (MMP)-9 (1:1,000, Cat no AF911; R\&D Systems, Inc., Minneapolis, MN, USA). Mouse monoclonal anti-beta actin antibody (1:20,000, Cat no ab6276; Abcam) was used as the loading control. Horseradish peroxidase (HRP)-conjugated, secondary antibodies (BioRad Laboratories Inc., Hercules, CA, USA) were used at an appropriate dilution. Finally, the membrane was exposed to SuperSignal West Pico Chemiluminescent Substrate (Thermo Fisher Scientific): luminal-based enhanced chemiluminescence HRP substrate (product code:10308449; Thermo Fisher Scientific) for chemiluminescent detection. Band density on the membranes was captured using the ImageQuant Imager (GE Healthcare Life Sciences, Chicago, IL, USA) and was calculated using ImageJ free software.

\section{Cell growth assay}

The sulforhodamine B (SRB) assay was used to determine growth inhibition, as described previously. ${ }^{22}$ In brief, transfected cells $\left(1 \times 10^{3}\right.$ cells per well) were seeded in five replicates into 96-well flat bottom microtiter plates and were incubated for $24,48,72$, and $96 \mathrm{~h}$ at $37^{\circ} \mathrm{C}$ in a humidified $5 \% \mathrm{CO}_{2}$ atmosphere. The culture medium was removed, and a $200 \mu \mathrm{L}$ aliquot of $10 \%(\mathrm{w} / \mathrm{v})$ ice-cold trichloroacetic acid (TCA) was added to each culture well. The plates were incubated at $40^{\circ} \mathrm{C}$ for $60 \mathrm{~min}$, and the TCA-treated cells were 
stained for $30 \mathrm{~min}$ with $0.4 \%$ (w/v) SRB in $1 \%$ (v/v) acetic acid for $30 \mathrm{~min}$ and subsequently washed with $1 \%$ (v/v) acetic acid. The plates were air dried, and the protein-bound dye was solubilized with $200 \mu \mathrm{L}$ of $10 \mathrm{mM}$ Tris base (pH 10.5) for $60 \mathrm{~min}$. Absorbance was measured at $540 \mathrm{~nm}$ using a microplate reader (Tecan, GmbH, Salzburg, Austria).

\section{Clonogenic cell survival assay}

The clonogenic assay determines the ability of a cell to proliferate indefinitely to form a large colony or a clone, as previously described with modifications. ${ }^{23}$ In brief, transfected cells were seeded $\left(2 \times 10^{2}\right.$ per well $)$ in a six-well plate. After 10 days of observation, the colonies formed were washed once with PBS, then fixed with $1 \mathrm{~mL} \mathrm{4 \%} \mathrm{paraformaldehyde} \mathrm{in} \mathrm{PBS,} \mathrm{and}$ incubated at room temperature for $20 \mathrm{~min}$. After incubating, the colonies were washed once with PBS, and the cells were stained with crystal violet diluted in ethanol. After $10 \mathrm{~min}$ of incubation, the dye was removed carefully by washing the plate under running tap water and allowed to air dry. The colonies were counted manually using Image J free software.

\section{Scratch wound-healing assay}

Transfected cells $\left(50 \times 10^{4}\right.$ cells $)$ were seeded in a $24-w e l l$ plate and grown until reaching $\sim 70 \%$ confluence. The confluent cell monolayers were scratched using a sterile p200 pipette tip and rinsed several times with PBS to remove cell debris. Cell migration to close the wound was examined at $0,12,24,48$, and $96 \mathrm{~h}$ by microscopy and digitally photographed. The breadth of the wound area was measured on the images, and the migration area was calculated using the following formula:

Migration area $=($ Area of original wound - Area of wound during healing)/Area of original wound

\section{Cell migration assay}

A cell migration assay was performed using a $6.5-\mathrm{mm}$ Transwell ${ }^{\circledR}$ with an $8.0-\mu \mathrm{m}$ Pore Polycarbonate Membrane Insert (Corning Incorporated, Corning, NY, USA). In brief, transfected cells $\left(4 \times 10^{4}\right.$ cells $)$ were seeded into the upper chamber with serum-free medium, and aliquots of complete HAM's F12 media were placed in the lower chamber. After $72 \mathrm{~h}$ of incubation for KKU-100 and $24 \mathrm{~h}$ for KKU-213, non-migrating cells residing at the upper filter were removed. Migrating cells that were attached to the underside of the filter were fixed with methanol and stained with hematoxylin overnight at room temperature. The number of migratory cells was quantified by counting them under a light microscope. The mean value of five fields at $\times 200$ magnification was calculated.

\section{Cell invasion assay}

A cell invasion assay was performed using Corning ${ }^{\circledR}$ BioCoat $^{\mathrm{TM}}$ Matrigel $^{\circledR}$ Invasion Chambers with an $8.0-\mu \mathrm{m}$ polyethylene terephthalate (PET) membrane (Discovery Labware, Inc., Bedford, MA, USA). In brief, a total of $4 \times 10^{4}$ transfected cells in serum-free media (HAM-F12) were seeded into the upper chamber of Transwell precoated Matrigel culture inserts (Becton Dickinson, Franklin Lakes, NJ, USA), and HAM-F12 medium supplemented with $10 \%$ (v/v) FBS was placed into the lower chamber. After incubation at $37^{\circ} \mathrm{C}$ for $72 \mathrm{~h}$ (KKU-100) and $24 \mathrm{~h}$ (KKU-213), cells at the upper surface of the filter were removed and those cells that had transversed through the Matrigel and invaded to the underside of the filter were fixed with absolute ethanol for $30 \mathrm{~min}$ and stained with hematoxylin. The invading cells (mean value of five fields at $\times 200$ magnification) were counted under the microscope.

\section{Cell cycle analysis}

Transfected cells were collected and fixed with $70 \%$ precooled ethanol overnight. The cell cycle phases were examined by flow cytometry (FACSCanto II $^{\mathrm{TM}}$, BD Biosciences) after staining with propidium iodide (Sigma-Aldrich Co., St Louis, MO, USA) in the dark for $30 \mathrm{~min}$ at $37^{\circ} \mathrm{C}$. Quantitation of cell cycle distribution was performed using BDFACSDiva ${ }^{\mathrm{TM}}$ Software (BD Biosciences). The percentage of cells in G0, G1, S, and G2 phases was calculated.

\section{Cell apoptosis analysis}

The Bax-to-Bcl-2 ratio of the transfected cells were determined by the Western blot analysis. Cell apoptosis was confirmed by annexin V staining. After treatment, cells were washed and resuspended in the staining buffer containing $1 \mu \mathrm{g} / \mathrm{mL}$ PI (Sigma-Aldrich Co.) and $0.025 \mu \mathrm{g} / \mathrm{mL}$ annexin V-FITC (BD Biosciences) at room temperature for $15 \mathrm{~min}$ in the dark. The stained cells were immediately determined using FACScanto II and analyzed using FACSDiva software (BD Biosciences).

\section{Statistical analysis}

The quantitative data are expressed as mean \pm SD. The SPSS statistical package for Windows version 19 (SPSS Inc., Chicago, IL, USA) and GraphPad Prism 5 software (GraphPad Software, Inc., La Jolla, CA, USA) were used for the statistical analysis. Results obtained from cell growth, 
clonogenic, cell migration, cell invasion assays, and cell cycle analysis were done in three independent trials with duplicates. The results from Western blotting were done in three independent trials. The significance was determined by the Student's $t$-test. The survival curve for low and high PGRN expression was constructed by the Kaplan-Meier method, and the log-rank test was used for analyzing the differences. Fisher's exact test was used to compare nominal data. The variables that correlated significantly with one of the parameters were included in the multivariate analysis. $P<0.05$ was defined as statistically significant.

\section{Results}

\section{Upregulation of PGRN expression was correlated with a poor prognosis and overall metastasis}

IHC results in this study revealed positive staining of PGRN protein in the cytoplasm of hyperplastic and tumor cells, whereas no or very weak staining was observed in the adjacent normal bile ducts (Figure 1A). Among the $50 \mathrm{CCA}$ tissues investigated, high expression of PGRN was observed in $26(52 \%)$ cases and low expression in $24(48 \%)$ cases. Patients with higher expressions of PGRN had a significantly shorter survival when compared to those patients with lower expressions of PGRN ( $P=0.04$; Figure 1B). There was a significant positive association between high PGRN expression levels and overall metastasis (Fisher's exact test: $P=0.002$ ). Age, gender, and histological grade did not show any association with PGRN protein levels (Table 1). Metastasis and persistent PGRN expression significantly favored survival in multivariate analysis (Table 2).

\section{Knockdown of PGRN expression reduced CCA cell proliferation, colony formation, migration, and invasion}

Western blotting results showed that both KKU-100 and KKU-213 cell lines expressed a high level of PGRN as opposed to immortalized cholangiocyte MMNK1 cells that showed a low-PGRN level (Figure 1C). The PGRN expression was significantly suppressed by transfecting the CCA

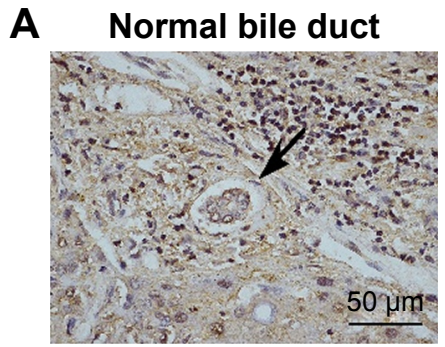

B

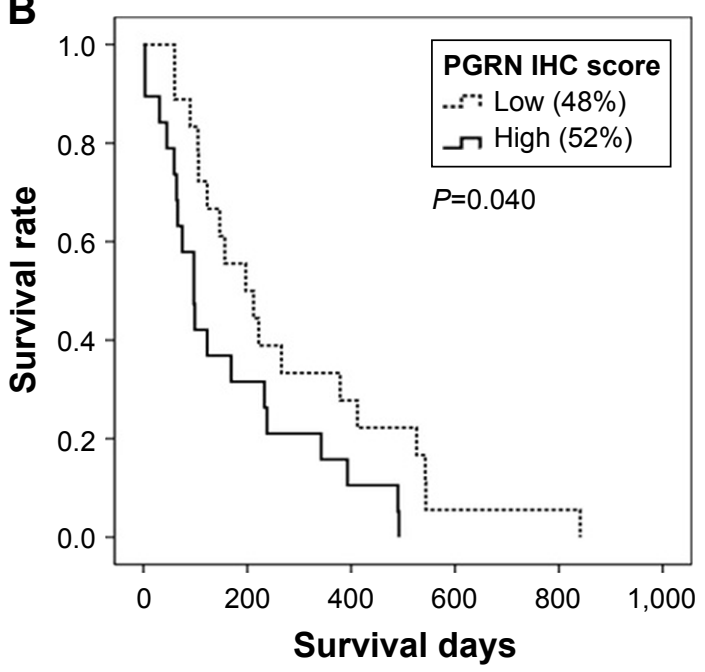

Low expression

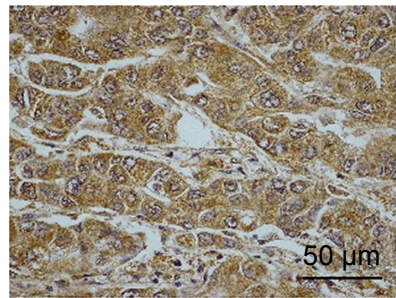

C
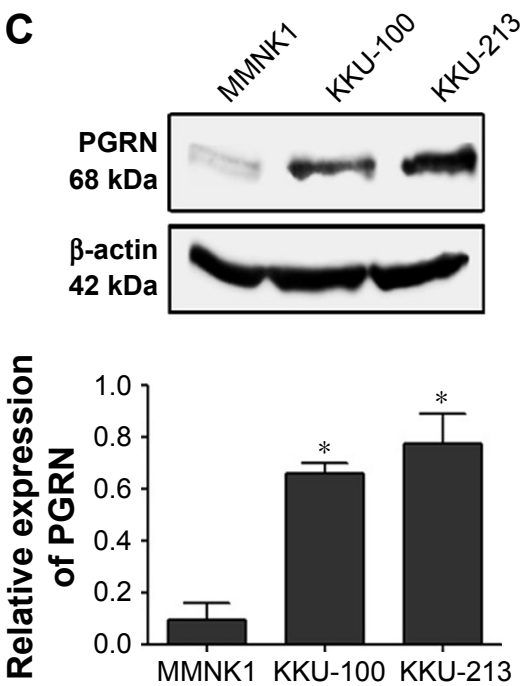

Figure I Upregulation of PGRN expression was correlated with poor prognosis and metastasis.

Notes: (A) Representative images of IHC demonstrating the high and low expressions of PGRN in CCA tissues, and a weak staining was observed in adjacent normal bile duct (arrow) (magnification, $\times 400$ ). (B) Survival analysis of PGRN expression in patients with CCA by the Kaplan-Meier method. Patients with high expression levels of PGRN correlated with shorter survival time $(P=0.040)$. (C) Western blot analysis of PGRN expression in KKU-I00 and KKU-2I3 CCA cell lines, compared to the immortalized cholangiocytes, MMNKI. The results were normalized to $\beta$-actin expression. The relative expression of PGRN are expressed as mean \pm SD of three independent experiments $(* P<0.05)$.

Abbreviations: CCA, cholangiocarcinoma; IHC, immunohistochemistry; PGRN, progranulin. 
Table I Univariate analysis for PGRN expression in human CCA tissues and the patient's clinicopathological data

\begin{tabular}{|c|c|c|c|c|}
\hline \multirow[t]{2}{*}{ Factors } & \multirow[t]{2}{*}{$\begin{array}{l}n \\
\text { (50 cases) }\end{array}$} & \multicolumn{2}{|c|}{$\begin{array}{l}\text { PGRN protein } \\
\text { expression }\end{array}$} & \multirow[t]{2}{*}{$P$-value } \\
\hline & & Low & High & \\
\hline Age (years) & & & & 0.413 \\
\hline$<60$ & 24 & 10 & 14 & \\
\hline$\geq 60$ & 26 & 14 & 12 & \\
\hline Gender & & & & 1.000 \\
\hline Female & 14 & 7 & 7 & \\
\hline Male & 36 & 17 & 19 & \\
\hline Metastasis & & & & $0.002^{\mathrm{a}}$ \\
\hline No metastasis & 26 & 18 & 8 & \\
\hline Metastasis & 24 & 6 & 18 & \\
\hline Histological grading & & & & 1.000 \\
\hline Non-papillary & 25 & 12 & 13 & \\
\hline Papillary & 25 & 12 & 13 & \\
\hline
\end{tabular}

Note: ${ }^{P}<0.05$ considered to indicate a statistically significance difference. Abbreviations: CCA, cholangiocarcinoma; PGRN, progranulin.

cells with siRNA targeting PGRN (siPGRN) compared with the siRNA non-targeting control (siControl; Figure 2A). We then observed the viability and proliferative activity of these transfected cells using the SRB assay. Results showed that the cell viability of both transfected cells decelerated the rate of cell proliferation compared with the siControls. Reduced cell proliferation was significantly observed starting at $72 \mathrm{~h}$ post-transfection in KKU-100 and at $48 \mathrm{~h}$ posttransfection in KKU-213 (both $P<0.05$; Figure 2B). We also performed a clonogenic assay to observe the ability of the transfected cells to form colonies. Our results showed $25 \%$

Table 2 Multivariate analysis including PGRN expression, gender, age, histologiocal type, and metastasis status

\begin{tabular}{|c|c|c|c|c|c|}
\hline \multirow[t]{2}{*}{ Variables } & \multirow{2}{*}{$\begin{array}{l}\text { Patients } \\
\text { ( } n=50 \text { cases) }\end{array}$} & \multirow{2}{*}{$\begin{array}{l}\text { Hazard } \\
\text { ratio }\end{array}$} & \multicolumn{2}{|l|}{$95 \% \mathrm{Cl}$} & \multirow[t]{2}{*}{$P$-value } \\
\hline & & & Lower & Upper & \\
\hline PGRN & & & & & $0.009^{a}$ \\
\hline Low expression & 16 & I & & & \\
\hline High expression & 34 & 2.707 & 1.190 & 6.162 & \\
\hline Gender & & & & & 0.665 \\
\hline Male & 33 & 1 & & & \\
\hline Female & 17 & 0.863 & 0.443 & 1.680 & \\
\hline Age (years) & & & & & 0.378 \\
\hline$<60$ & 24 & I & & & \\
\hline$\geq 60$ & 26 & 1.344 & 0.697 & 2.591 & \\
\hline Histological type & & & & & 0.349 \\
\hline Non-papillary & 25 & 1 & & & \\
\hline Papillary & 25 & 0.748 & 0.407 & 1.375 & \\
\hline Metastasis status & & & & & $0.000^{\mathrm{a}}$ \\
\hline No metastasis & 26 & I & & & \\
\hline Metastasis & 24 & 5.091 & 2.280 & 11.366 & \\
\hline
\end{tabular}

Note: ${ }^{a}<0.05$ considered to indicate a statistically significance difference. Abbreviation: PGRN, progranulin. reduction of colony formation on day 10 post-transfection for KKU-100 and a 50\% reduction of colony formation on day 7 of post-transfection for KKU-213 compared with the siControls (both $P<0.05$; Figure 3 ).

The lateral migration ability of siPGRN-transfected cells was also investigated using the in vitro wound-healing assay. Cell migration activity was observed after every $6 \mathrm{~h}$ until the siControl-transfected cells completely spread to close the wound. The siPGRN-transfected KKU-100 cells showed slower migration and an inability to completely close the wound at $96 \mathrm{~h}$ compared with the siControl-transfected cells $(P<0.05)$. The siPGRN-transfected KKU-213 cells also showed slower migration and an inability to completely close the wound at $24 \mathrm{~h}$ compared with the siControl cells $(P<0.05$; Figure 4).

The modified Boyden chamber transwell was performed to investigate the transmigration activity of the transfected cells. Results showed lesser number of migrating cells when KKU-100 cells were transfected with siPGRN, and a $65 \%$ reduction of cell migration was significantly observed $(P<0.05)$. The siPGRN-transfected KKU-213 cells resulted in $70 \%$ reduction of cell migration compared with the siControl cells $(P<0.05$; Figure 5A).

The ability of the siPGRN-transfected CCA cells to digest the matrigel and invade the underside of the membrane was also performed, and the results showed reduction of the ability of KKU-100 transfected cells to invade by $70 \%$ $(P<0.05)$ and KKU-213 by $60 \%$ compared with that of the siControl cells $(P<0.05$; Figure $5 \mathrm{~B})$.

\section{Knockdown of PGRN expression downregulates the expression of PI3K and phosphorylation of Akt}

The signaling pathway possibly involved in modulating cell proliferation, apoptosis, and motility was investigated in siPGRN-transfected cells using Western blotting. Results showed the downregulation of PI3K and pAkt in both siPGRN-transfected KKU-100 and KKU-213 cell lines compared with that in the siControl cells (both $P<0.05$; Figure 6).

\section{Knockdown of PGRN expression dysregulates the CCA cell cycle at the GI phase and promotes apoptosis}

Cell cycle analysis of siPGRN-transfected cells showed an increase of 3\% parental cells at the G1 phase in both KKU-100 and KKU-213 cell lines (both $P<0.05$; Figure 7A). Investigating the molecular changes at the $\mathrm{G} 1$ phase revealed 

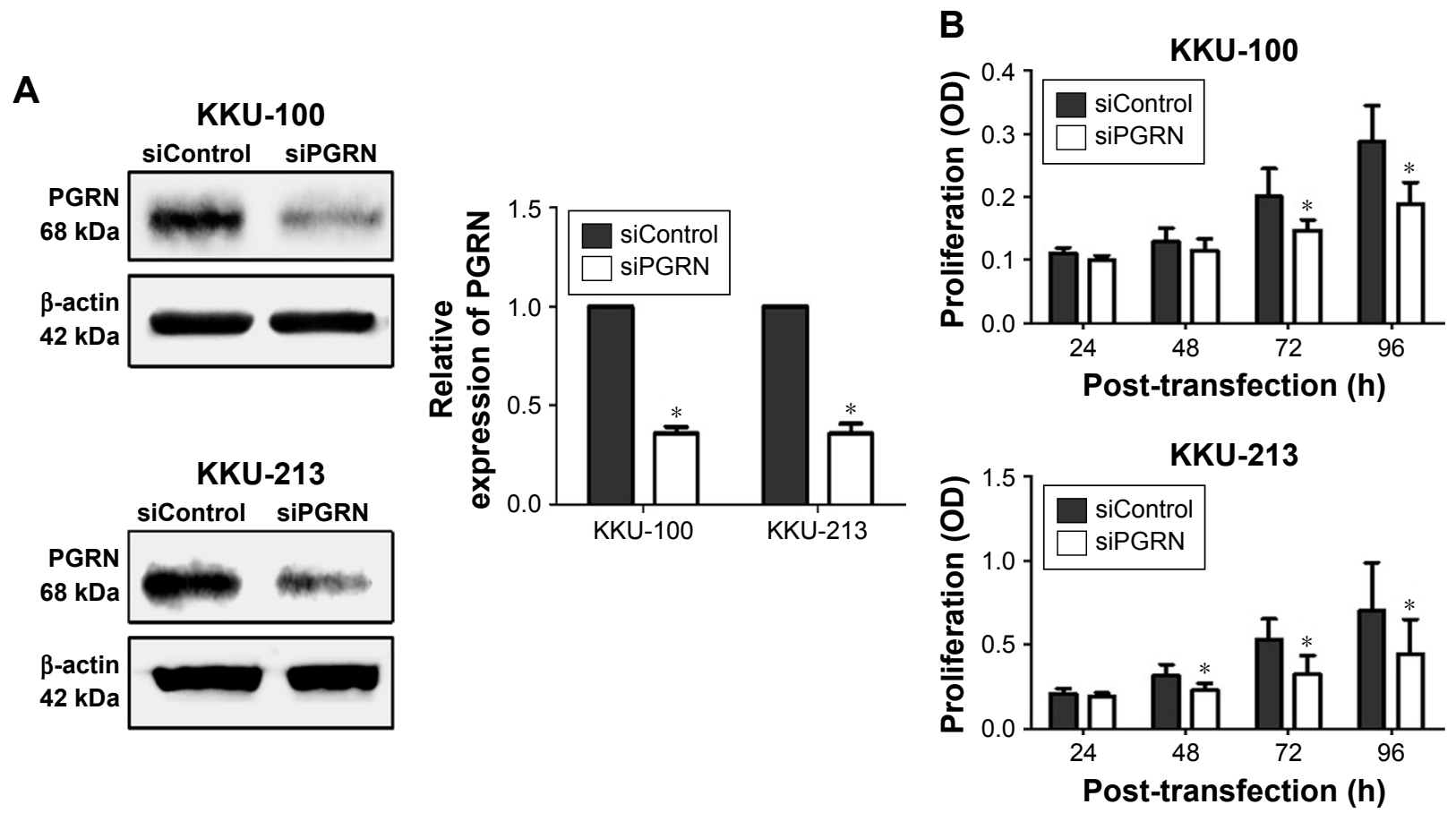

Figure 2 Knockdown of PGRN expression reduced CCA cells proliferation.

Notes: (A) Western blot analysis of PGRN expression when transfected with siControl or siPGRN in KKU-100 and KKU-2। 3 cells. (B) The proliferation of transfected cell lines. Data are expressed as mean $\pm S D$ of three independent experiments $\left({ }^{*} P<0.05\right)$.

Abbreviations: CCA, cholangiocarcinoma; PGRN, progranulin; siControl, siRNA non-targeting control; siPGRN, siRNA targeting PGRN.

a significant decrease in the expressions of cyclin D1 and CDK4 in KKU-100- and KKU-213-transfected cells compared with the siControl cells (both $P<0.05$; Figure 7B).

The involvement of PGRN in the apoptotic activity of CCA cells was investigated by examining the molecular changes in the expression of Bax and Bcl-2. Results showed an increase in the ratio of Bax-to-Bcl-2 protein observed in siRNA-PGRN-transfected KKU-100 and KKU-213 cells compared with the siControl cells (both $P<0.05$; Figure 8A).
Increased apoptotic cells were also observed in siRNAPGRN-transfected cells using the annexin V/PI staining $(P<0.05$; Figure $8 \mathrm{~B})$.

\section{Knockdown of PGRN expression decreased the expression of mesenchymal biomarkers in CCA cells}

Most tumor cells express the mesenchymal-like characteristics that enable the cells to migrate and invade the surrounding

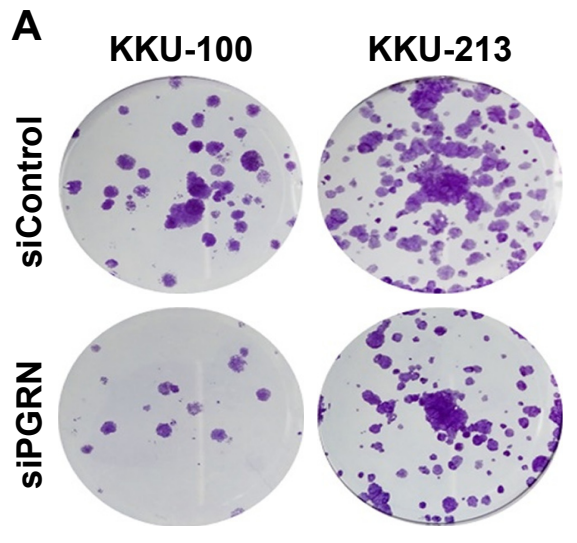

B

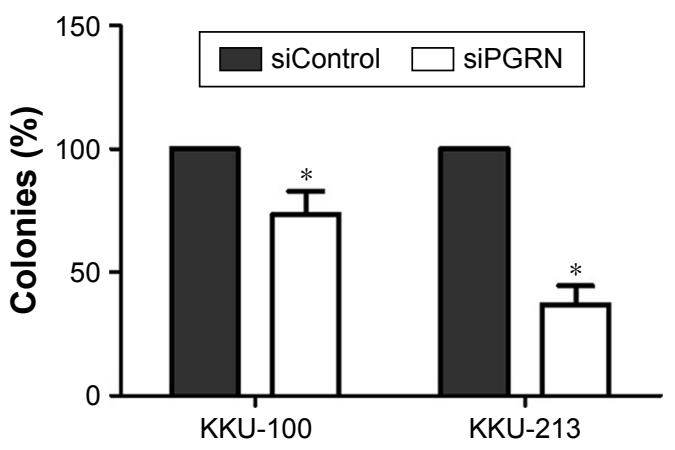

Figure 3 Knockdown of PGRN expression reduced the ability of CCA cells to form colony.

Notes: (A) Representative images of crystal violet staining of KKU-I00 and KKU-2I3 cell colony formation assays. (B) Colonies containing $>50$ cells were counted. Quantified results were expressed as a percentage of the siControl group, setting at $100 \%$. Data are expressed as mean \pm SD of three independent experiments ( $* P<0.05$ ). Abbreviations: CCA, cholangiocarcinoma; PGRN, progranulin; siControl, siRNA non-targeting control; siPGRN, siRNA targeting PGRN. 
A

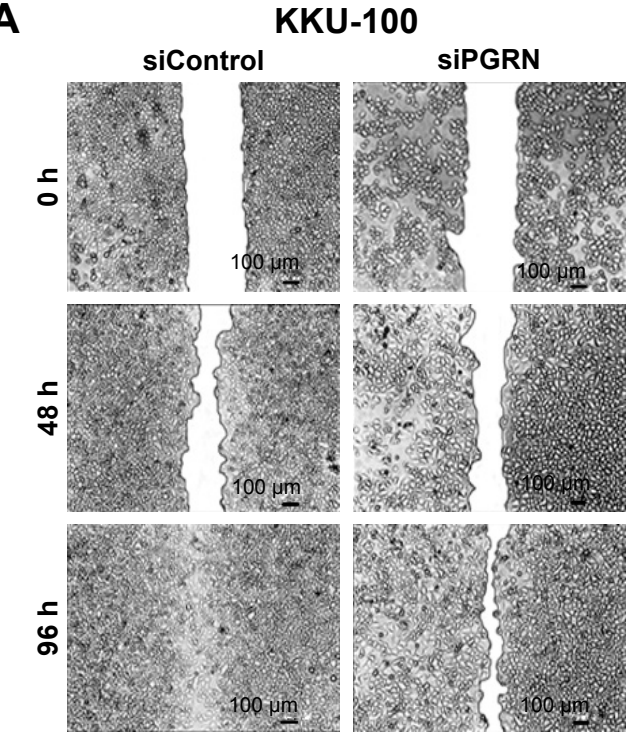

B

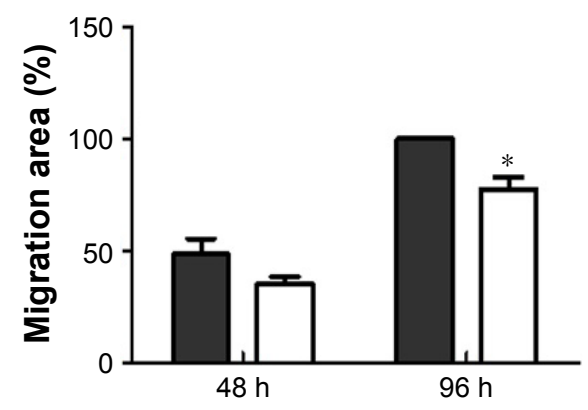

Post-transfection
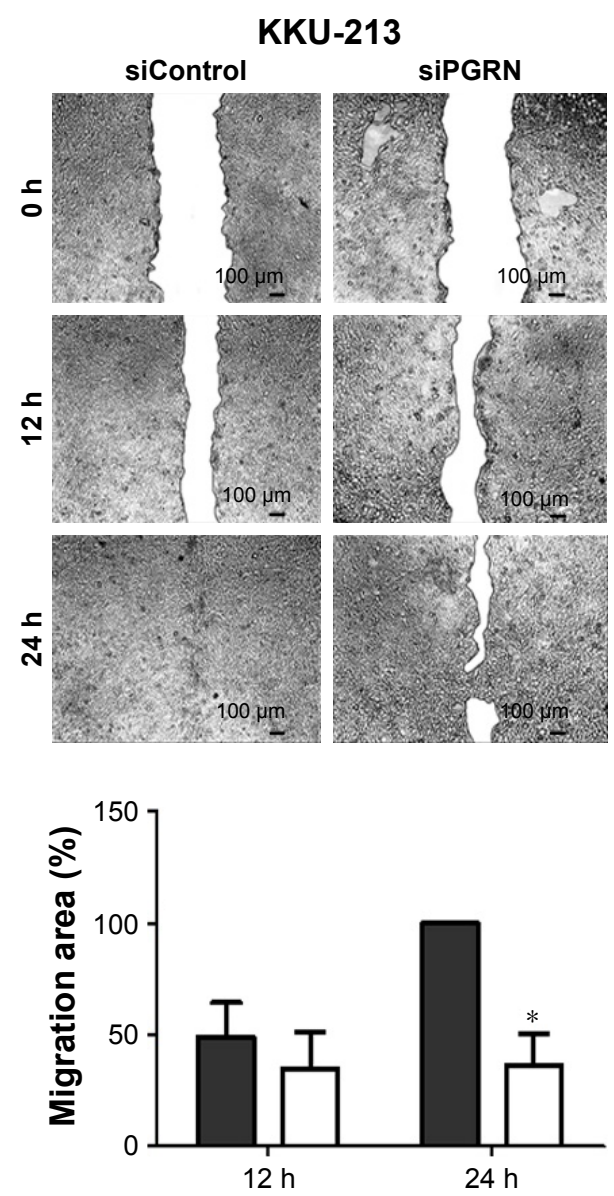

Post-transfection

siControl $\square$ siPGRN

Figure 4 Knockdown of PGRN expression reduced the ability of CCA cells to migrate laterally.

Notes: (A) Micrographs of wound healing assays for KKU-I00 and KKU-2I 3 cells transfected with siControl or siPGRN. Images were obtained at 0 , I2, 24,48 , and $96 \mathrm{~h}$ (magnification, $\times 100)$. (B) Percentage of wound closure for the corresponding cell lines. Data were obtained from two independent experiments in triplicates $(* P<0.05)$.

Abbreviations: CCA, cholangiocarcinoma; PGRN, progranulin; siControl, siRNA non-targeting control; siPGRN, siRNA targeting PGRN.

tissues. The expression of mesenchymal biomarkers was investigated in this study. Our results showed expressions of vimentin, snail, and MMP-9 in CCA cell lines, and a reduction in the expression of these biomarkers was observed in siRNAPGRN-transfected KKU-100 and KKU-213 cells compared with that in the siControl cells (both $P<0.05$; Figure 9).

\section{Discussion}

PGRN, the growth factor, is a secreted glycoprotein known to play an important role in the regulation of normal tissue development, cell cycle progression, and cell motility. ${ }^{24}$ PGRN is expressed at higher levels in numerous cancers than in normal tissues, and this overproduction is correlated with a poor prognosis and high tumor severity. ${ }^{25}$ The reduction of tumor formation after PGRN knockdown provides considerable evidence for its crucial role in tumor progression. ${ }^{26,27}$ Previous studies on PGRN overproduction emphasize tumor cell growth and the signaling pathways involved in cell proliferation. ${ }^{16-18,28,29}$ Other studies demonstrate the involvement of PGRN in cell migration and invasion; ${ }^{16,28-30}$ however, the mechanisms of PGRN involvement in CCA cell proliferation and motility needed further investigation. Understanding the biological role of PGRN in the progression of tumors could provide a promising target for the development of new cancer therapies.

Our study revealed high expression of PGRN in human CCA tissues compared to adjacent non-tumor areas. This IHC finding is consistent with a previous study showing increased PGRN immunoreactivity in CCA tissues. ${ }^{18}$ Our study also demonstrated that high PGRN expression is significantly associated with patient's shorter survival and the likelihood of finding metastasis. Metastasis and PGRN expression were the only independent prognostic variables in the multivariate analysis. This study supports the previous finding that PGRN expression could possibly serve as a potential prognostic biomarker for predicting the prognosis of patients. ${ }^{31}$ 

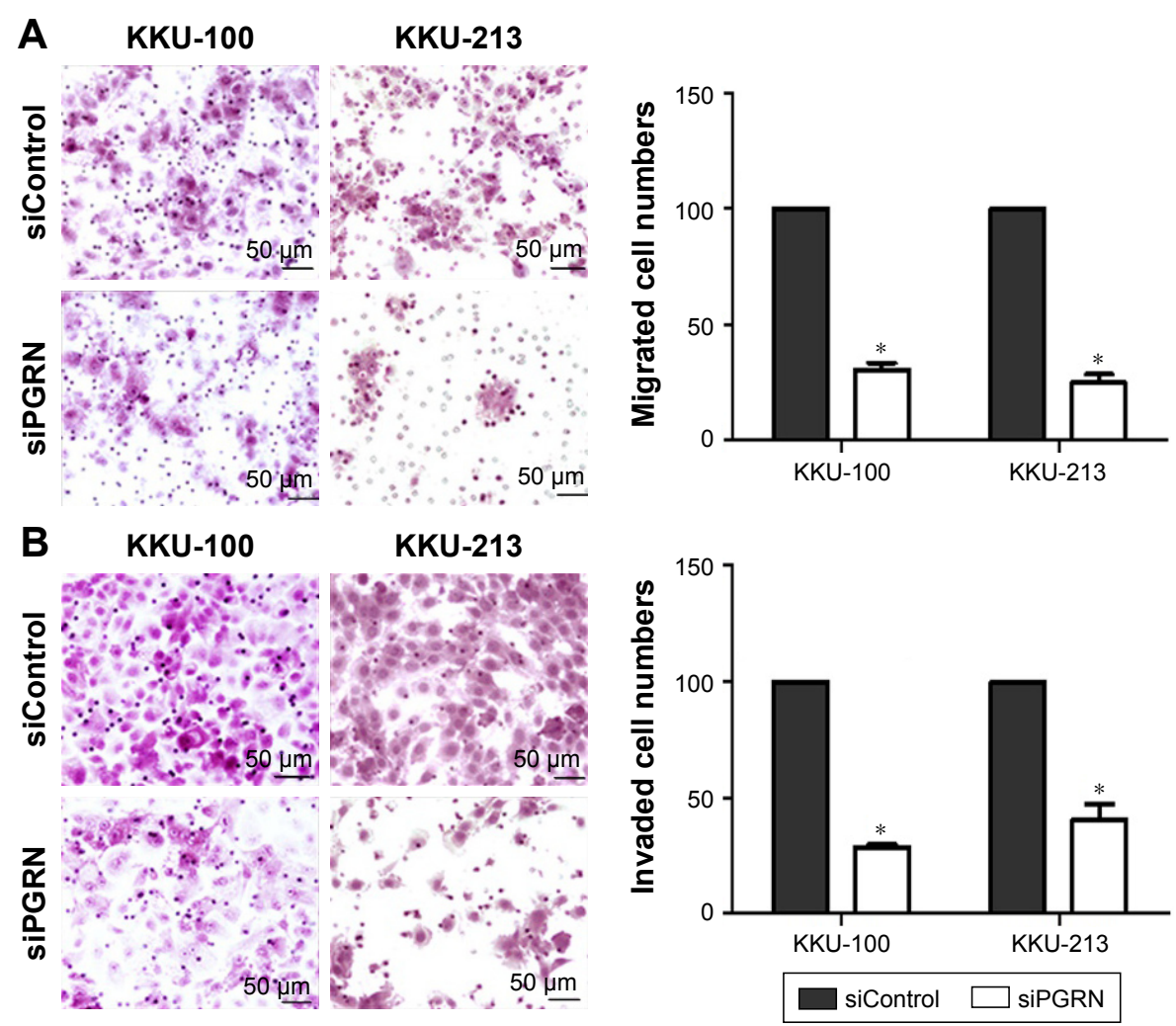

Figure 5 Knockdown of PGRN expression reduced migration and invasiveness of CCA cells.

Notes: (A) Micrographs of the transwell migration assay and (B) invasion assay in the KKU-100 and KKU-213 cells (magnification, $\times 200$ ). Migrated and invaded cell numbers are expressed as a percentage of the siControl group, setting at 100\%. Data are expressed as mean \pm SD of three independent experiments $(* P<0.05)$.

Abbreviations: CCA, cholangiocarcinoma; PGRN, progranulin; siControl, siRNA non-targeting control; siPGRN, siRNA targeting PGRN.
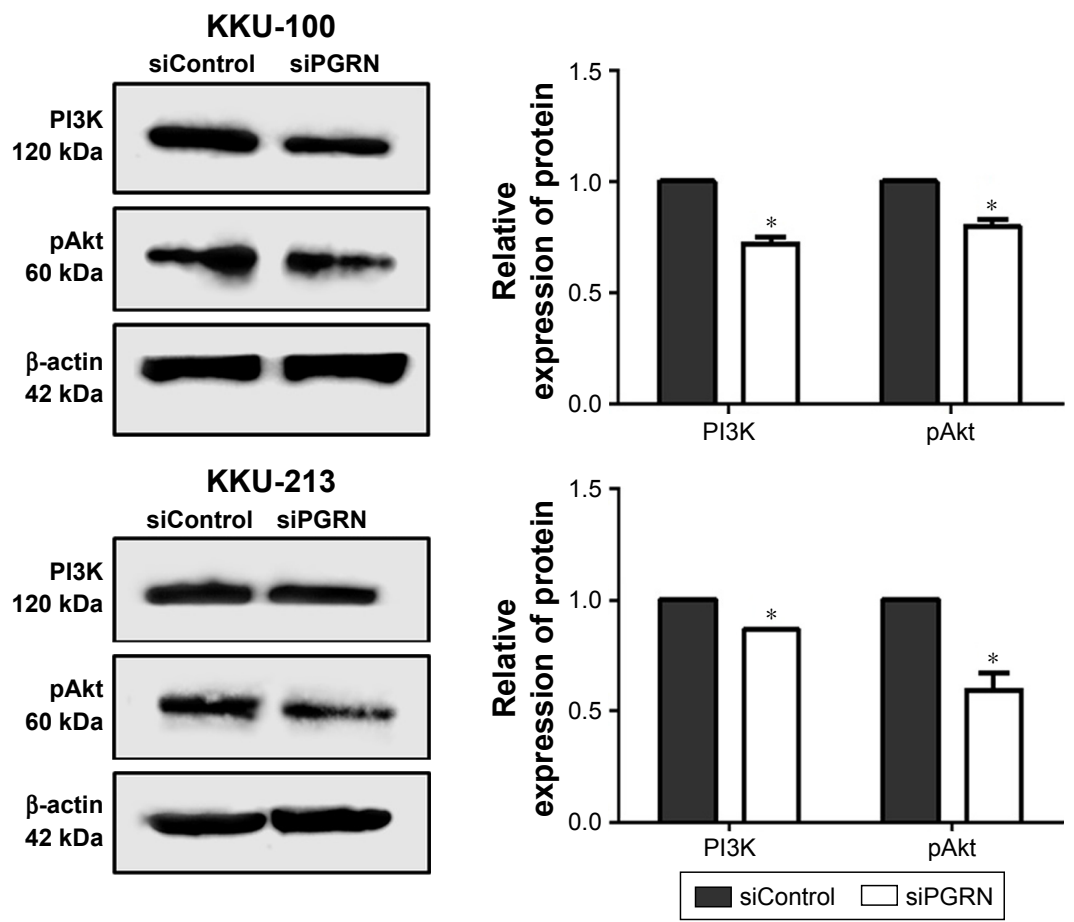

Figure 6 Knockdown of PGRN downregulated the CCA cell expression for PI3K and Akt phosphorylation.

Notes: Western blot analysis of PI3K and PAkt expressions in KKU-100- and KKU-2।3-transfected cells. The relative expression of proteins is expressed as mean \pm SD of three independent experiments $(* P<0.05)$.

Abbreviations: CCA, cholangiocarcinoma; PGRN, progranulin; PAkt, phosphorylated Akt, also known as protein kinase B; PI3K, phosphatidylinositol 3'-kinase; PGRN, progranulin; siControl, siRNA nontargeting control; siPGRN, siRNA targeting PGRN. 

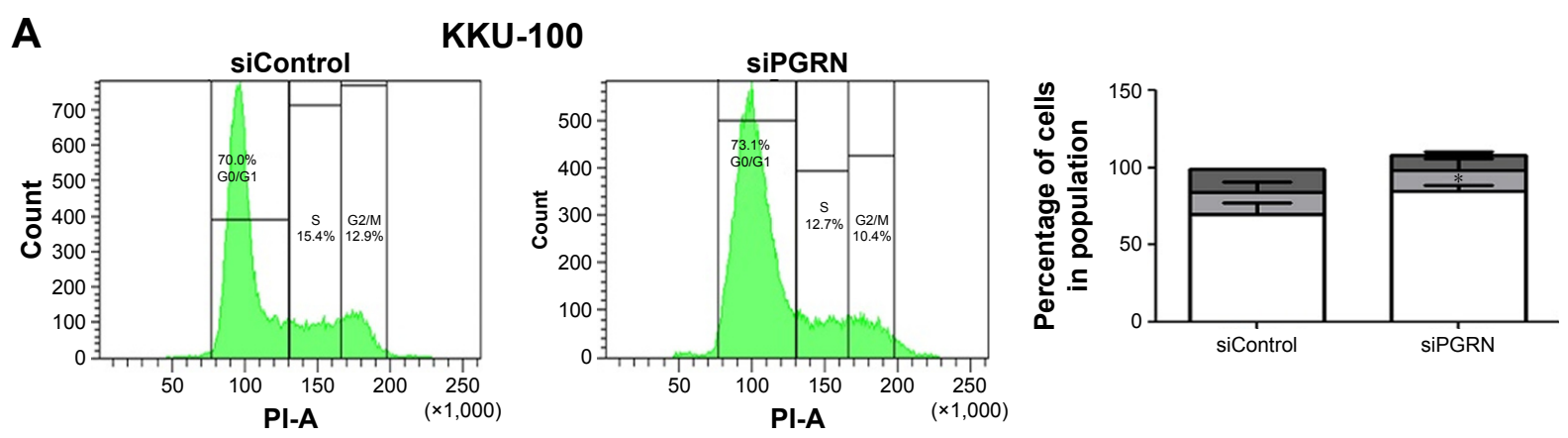

KKU-213
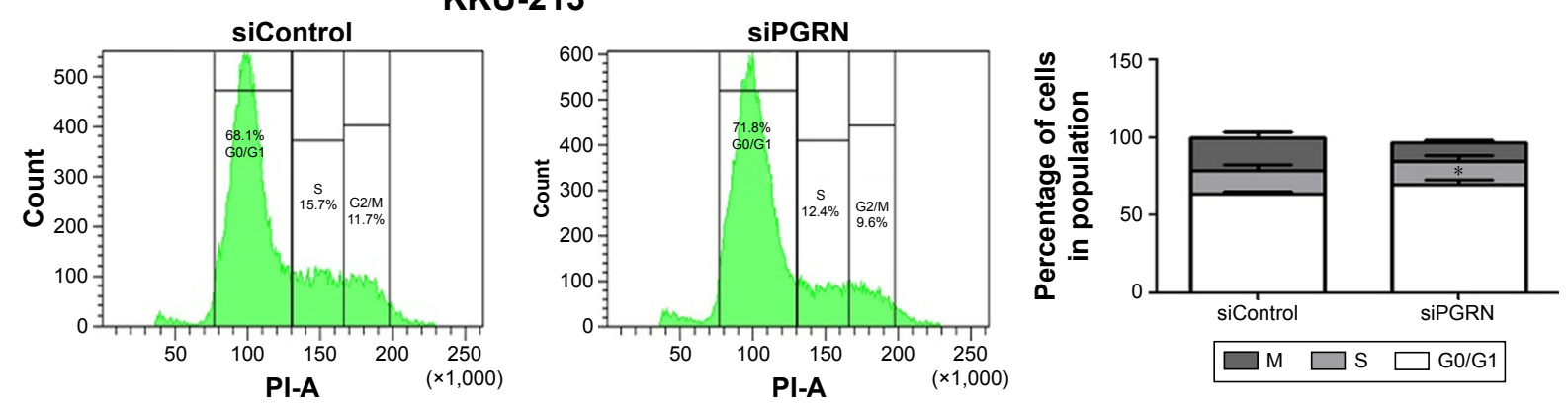

B

KKU-100
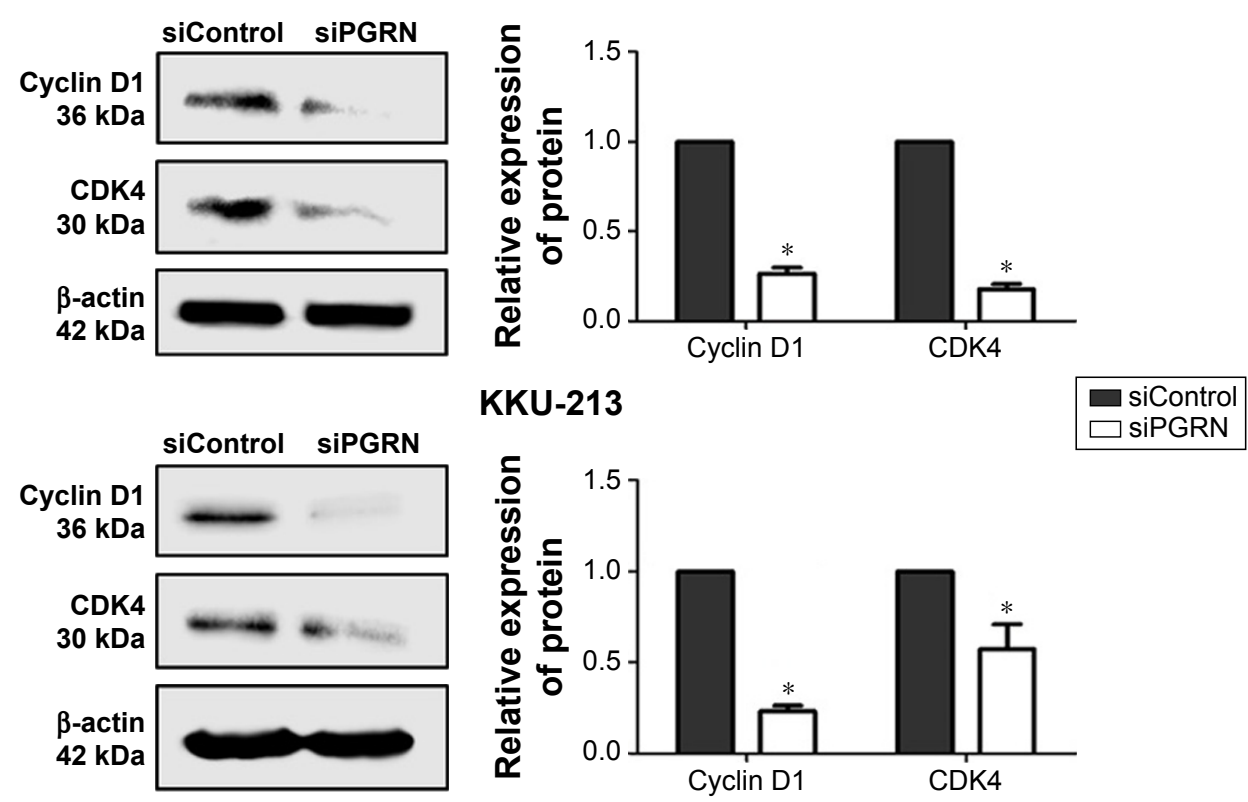

Figure 7 Knockdown of PGRN expression downregulated the CCA cell expression for cyclin DI and CDK4.

Notes: (A) Flow cytometric analysis of KKU-100- and KKU-2I3-transfected cells. The percentage distribution of cells in different phases of the cell cycle was analyzed from three independent experiments. (B) Western blot analysis of cyclin DI and CDK4 expressions in KKU-I00-and KKU-2I3-transfected cells. The relative expression of proteins is expressed as mean $\pm S D$ of three independent experiments $(* P<0.05)$.

Abbreviations: CCA, cholangiocarcinoma; CDK4, cyclin dependent kinase 4; PGRN, progranulin; siControl, siRNA non-targeting control; siPGRN, siRNA targeting PGRN.

To understand the involvement of PGRN in the progression of CCA, we interfered with the expressions of PGRN in two CCA cell lines, KKU-213 and KKU-100, using siRNA transfection. Our results showed that cells transfected with siPGRN showed a significantly reduced rate of proliferation and colony formation, which is also consistent with previous findings for the crucial role of PGRN as a novel growth factor regulating tumor growth. ${ }^{17,18,32}$

PGRN knockdown in CCA cells also showed suppression of PI3K and pAkt in protein levels, indicating the involvement of PGRN in stimulating the activity of this signaling pathway in CCA cells. Our result is consistent with the study 
A

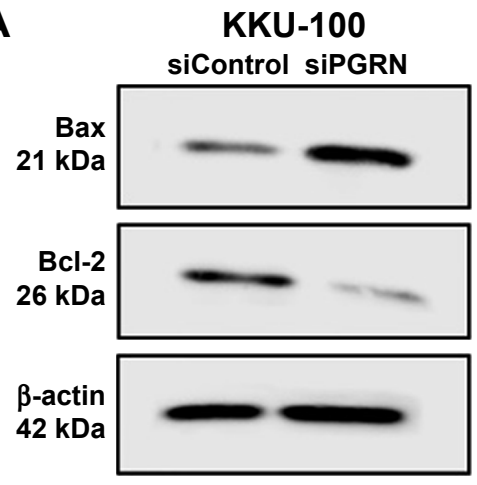

KKU-213

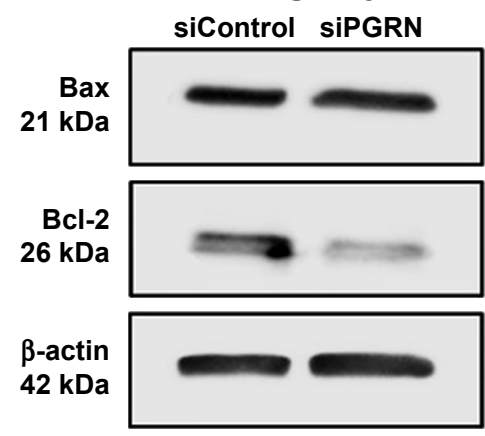

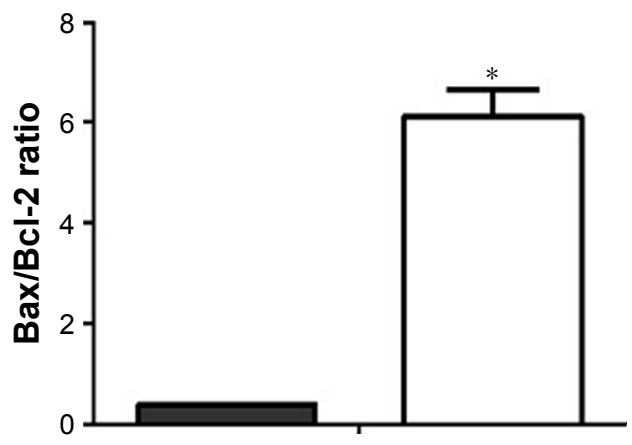

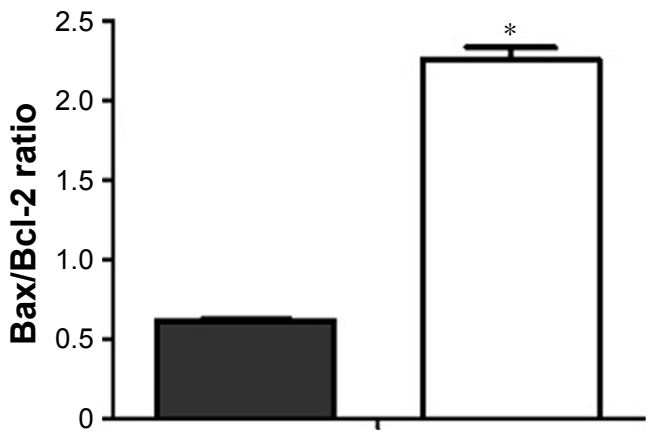

siControl $\square$ siPGRN

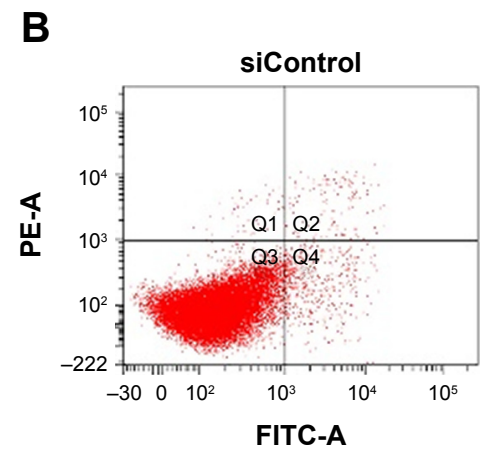

KKU-100
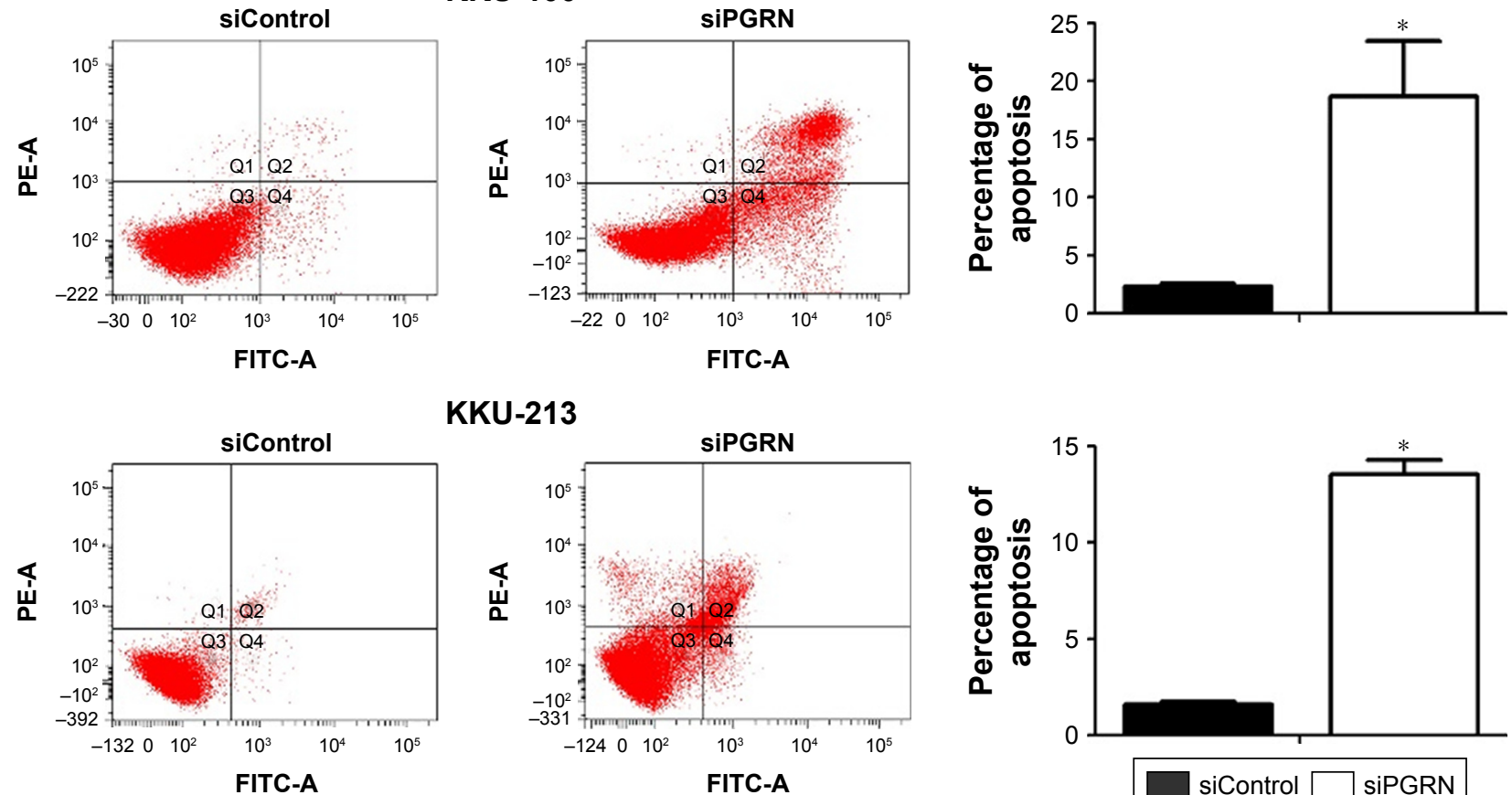

\section{KKU-213}
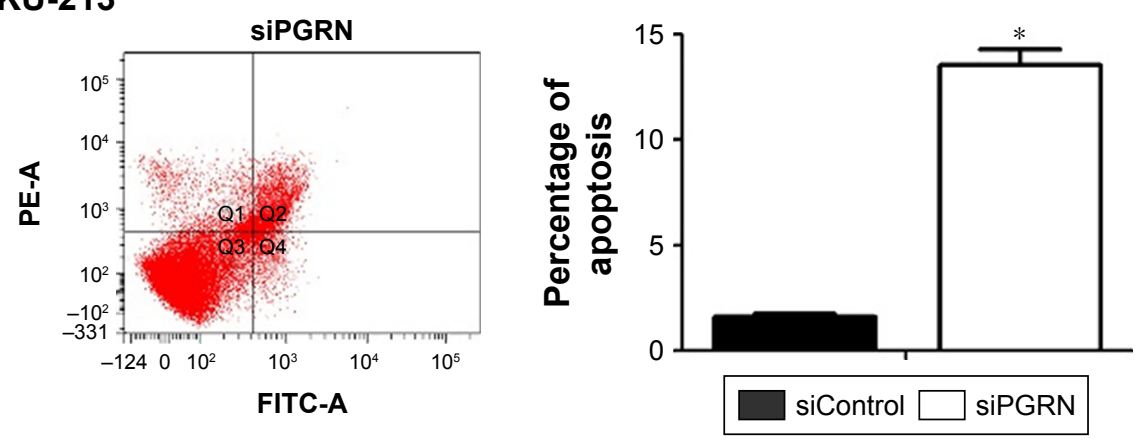

Figure 8 Knockdown of PGRN expression induced apoptosis in CCA cells.

Notes: (A) Western blot analysis of Bax and Bcl-2 expressions in KKU-I00 and KKU-2। 3 transfected cells. The ratio of Bax-to-Bcl-2 was analyzed from three independent experiments. (B) Cell apoptosis was confirmed using flow cytometry with annexin V-FITC/PI staining; in all four plots, the right upper and right lower quadrants show apoptotic cells. The proportion of apoptotic cells in KKU-I00- and KKU-2/3-transfected cells are expressed as mean \pm SD from two independent experiments with consistent results $(* P<0.05)$.

Abbreviations: Bax, also known as bcl-2 like protein 4; Bcl-2, B-cell lymphoma 2; CCA, cholangiocarcinoma; PGRN, progranulin; PI, propidium iodide; siControl, siRNA nontargeting control; siPGRN, siRNA targeting PGRN. 
A

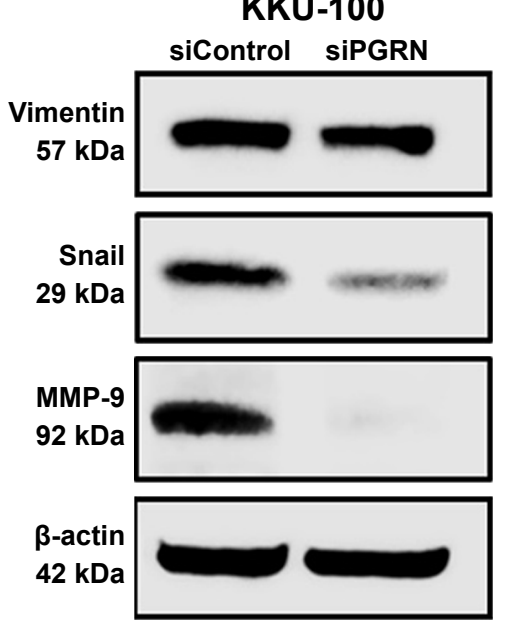

B

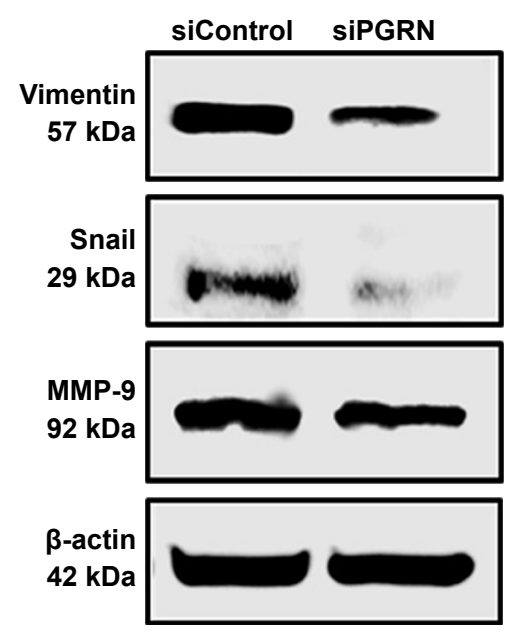

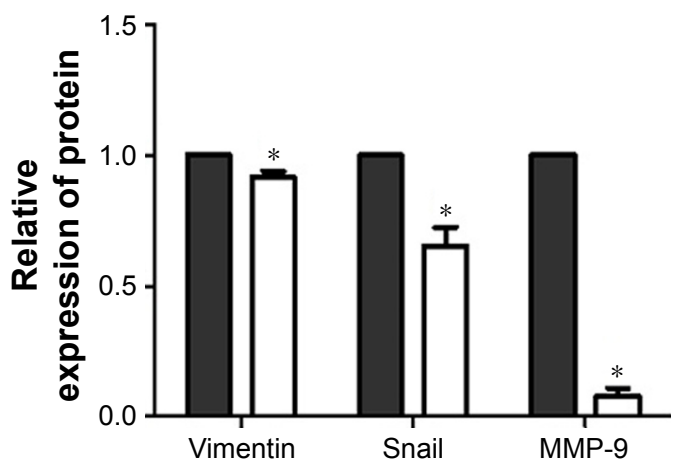

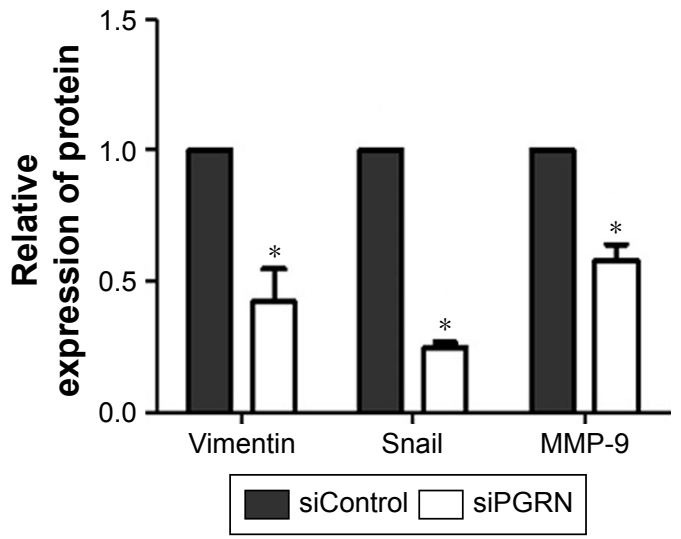

Figure 9 Knockdown of PGRN decreased the expression of mesenchymal biomarkers in CCA.

Notes: Western blot analysis of vimentin, snail, and MMP-9 expressions in (A) KKU-100 and (B) KKU-2I3-transfected cells. The relative expression of proteins is expressed as mean $\pm \mathrm{SD}$ of three independent experiments $(* P<0.05)$.

Abbreviations: CCA, cholangiocarcinoma; MMP, metalloproteinase; PGRN, progranulin; siControl, siRNA non-targeting control.

by Frampton et al, demonstrating the growth-promoting effect of PGRN in CCA cells via the activation of Akt signaling. ${ }^{18}$ The increased activation of PI3K/Akt signaling was also observed in CCA when compared with normal adjacent tissues. ${ }^{33,34}$ In many cancers, the PI3K/Akt pathway is overactive, and, as a consequence of this overactivity, there is enhanced proliferative activity of the tumor cells. ${ }^{16,35}$

We further investigated the changes in cell cycle activity in PGRN knockdown cells. Our results showed an accumulation of transfected cells at the G1 phase, indicating the involvement of PGRN in promoting cell proliferation at this phase. Considering the key molecular players at the G1 phase, cyclin D1 and CDK4 showed decreased levels in both knockdown cell lines. We investigated the apoptotic activity of CCA revealing that knockdown of PGRN-modulated apoptosis by reversing the Bax-to-Bcl-2 ratio. Increased cell apoptosis was confirmed from flow cytometry analysis stained with annexin V-FITC/PI. Our data suggest that PGRN might control CCA cell survival via the PI3K/Akt pathway and play an important role in the prevention of apoptosis.

The significant reduction in the abilities of PGRN knockdown cells for migration and invasion obtained from this study prompted us to investigate the role of PGRN in the EMT. Emerging evidence suggests that EMT plays an important role in tumorigenesis. This is a major mechanism responsible for mediating invasiveness and metastasis. ${ }^{36}$ Occurrence of this phenomenon has been previously observed in CCA tissues and cell lines where the biomarkers for mesenchymal phenotype, such as N-cadherin, S100A4, and the transcription factors Snail, Twist and ZEB2, were reported to express at higher levels compared to controls. ${ }^{37-39}$ Moreover, the expression levels of these biomarkers for the mesenchymal phenotype are inversely correlated with the expression of the epithelial biomarkers E-cadherin and CK-19. ${ }^{37}$ 
The results obtained from this study show that CCA cells expressing PGRN possess mesenchymal-like characteristics, expressing vimentin and the EMT-inducing transcription factor, snail. These CCA cells also expressed the MMP-9, a class of matrix MMP whose main function is to degrade and remodel the extracellular matrix (ECM). The present finding on MMP is consistent with previous results in which MMP-2 and MMP-9 were upregulated and inversely correlated to the reversion-inducing cysteine-rich protein with kazal motifs (RECK), a metastasis suppressor protein that inhibits the secretion and proteolytic activities of MMPs. ${ }^{40}$ Our findings demonstrate that siRNA-suppressed PGRN expression in CCA cells leads to decreased levels of mesenchymal biomarkers vimentin and snail, and hence a reduction in the abilities of cells to migrate and invade under the role of MMP-9. This strongly suggests that PGRN plays a critical role in tumor metastasis mediated by the EMT process. Understanding the mechanisms by which PGRN regulates tumor growth and metastasis needs to be further investigated.

\section{Conclusion}

The growth factor PGRN is upregulated in the tissues of patients with CCA. This upregulation is correlated with a poor prognosis, suggesting that $\mathrm{PGRN}$ could be a prognostic marker for CCA. The mechanism of action by which PGRN regulates CCA cell proliferation, apoptosis, and EMT might be mediated by the PI3K/Akt pathway.

\section{Acknowledgments}

This work was supported by a grant from Mid-Career Grant (RSA5980012), Thailand Research Fund (to NN), a grant from Khon Kaen University (to NN), a grant from CASCAP Program (to NN), and a grant from the Faculty of Medicine, Khon Kaen University for supporting the $\mathrm{PhD}$ program (to MD) (IN59339). We would like to acknowledge Prof Trevor N Petney for editing the manuscript via Publication Clinic KKU, Thailand.

\section{Author contributions}

$\mathrm{MD}, \mathrm{WL}, \mathrm{AT}$, and NN planned experiments; MD performed experiments; MD, WL, AT, MT, PS-N, AT, PY, and NN analyzed the data; WL, AT, PY, and NN contributed reagents and/or other essential materials; $\mathrm{MD}$ and $\mathrm{NN}$ wrote the manuscript. All authors read and revised the manuscript.

\section{Disclosure}

The authors report no conflicts of interest in this work.

\section{References}

1. Doherty B, Nambudiri VE, Palmer WC. Update on the diagnosis and treatment of cholangiocarcinoma. Curr Gastroenterol Rep. 2017;19(1):2.

2. Yongvanit P, Pinlaor S, Loilome W. Risk biomarkers for assessment and chemoprevention of liver fluke-associated cholangiocarcinoma. $J$ Hepatobiliary Pancreat Sci. 2014;21(5):309-315.

3. Khuntikeo N, Loilome W, Thinkhamrop B, Chamadol N, Yongvanit P. A comprehensive public health conceptual framework and strategy to effectively combat cholangiocarcinoma in Thailand. PLoS Negl Trop Dis. 2016;10(1):e0004293.

4. Kirstein MM, Vogel A. Epidemiology and risk factors of cholangiocarcinoma. Visc Med. 2016;32(6):395-400.

5. Sudsarn P, Wongchalee N, Boonmars T, et al. Sex differences in opisthorchiosis and the development of cholangiocarcinoma in Syrian hamster model. Parasitol Res. 2014;113(3):829-835.

6. Songserm N, Promthet S, Pientong C, Ekalaksananan T, Chopjitt P, Wiangnon $\mathrm{S}$. Gene-environment interaction involved in cholangiocarcinoma in the Thai population: polymorphisms of DNA repair genes, smoking and use of alcohol. BMJ Open. 2014;4(10):e005447.

7. Wakabayashi M, McKetin R, Banwell C, et al. Alcohol consumption patterns in Thailand and their relationship with non-communicable disease. BMC Public Health. 2015;15:1297.

8. Miwa M, Honjo S, You G, et al. Genetic and environmental determinants of risk for cholangiocarcinoma in Thailand. World J Gastrointest Pathophysiol. 2014;5(4):570-578.

9. Mancino A, Mancino MG, Glaser SS, et al. Estrogens stimulate the proliferation of human cholangiocarcinoma by inducing the expression and secretion of vascular endothelial growth factor. Dig Liver Dis. 2009;41(2):156-163.

10. DeMorrow S. Cholangiocarcinoma: estrogen-induced autocrine effects of VEGF on cell proliferation. Dig Liver Dis. 2009;41(2):164-165.

11. Marzioni M, Torrice A, Saccomanno S, et al. An oestrogen receptor beta-selective agonist exerts anti-neoplastic effects in experimental intrahepatic cholangiocarcinoma. Dig Liver Dis. 2012;44(2):134-142.

12. Banales JM, Cardinale V, Carpino G, et al. Expert consensus document: Cholangiocarcinoma: current knowledge and future perspectives consensus statement from the European Network for the Study of Cholangiocarcinoma (ENS-CCA). Nat Rev Gastroenterol Hepatol. 2016; 13(5):261-280.

13. Ong CH, Bateman A. Progranulin (granulin-epithelin precursor, PC-cell derived growth factor, acrogranin) in proliferation and tumorigenesis. Histol Histopathol. 2003;18(4):1275-1288.

14. Demorrow S. Progranulin: a novel regulator of gastrointestinal cancer progression. Transl Gastrointest Cancer. 2013;2(3):145-151.

15. Tanimoto R, Lu KG, Xu SQ, et al. Mechanisms of progranulin action and regulation in genitourinary cancers. Front Endocrinol (Lausanne). 2016;7:100.

16. Liu F, Zhang W, Yang F, et al. Interleukin-6-stimulated progranulin expression contributes to the malignancy of hepatocellular carcinoma cells by activating mTOR signaling. Sci Rep. 2016;6:21260.

17. Lu Y, Zheng L, Zhang W, et al. Growth factor progranulin contributes to cervical cancer cell proliferation and transformation in vivo and in vitro. Gynecol Oncol. 2014;134(2):364-371.

18. Frampton $G$, Invernizzi $P$, Bernuzzi $F$, et al. Interleukin-6-driven progranulin expression increases cholangiocarcinoma growth by an Akt-dependent mechanism. Gut. 2012;61(2):268-277.

19. Ye X, Weinberg RA. Epithelial-mesenchymal plasticity: a central regulator of cancer progression. Trends Cell Biol. 2015;25(11):675-686.

20. Lamouille S, Xu J, Derynck R. Molecular mechanisms of epithelialmesenchymal transition. Nat Rev Mol Cell Biol. 2014;15(3):178-196.

21. Maruyama M, Kobayashi N, Westerman KA, et al. Establishment of a highly differentiated immortalized human cholangiocyte cell line with SV40T and hTERT. Transplantation. 2004;77(3):446-451.

22. Vichai V, Kirtikara K. Sulforhodamine B colorimetric assay for cytotoxicity screening. Nat Protoc. 2006;1(3):1112-1116.

23. Munshi A, Hobbs M, Meyn RE. Clonogenic cell survival assay. Methods Mol Med. 2005;110:21-28. 
24. He Z, Bateman A. Progranulin (granulin-epithelin precursor, PC-cellderived growth factor, acrogranin) mediates tissue repair and tumorigenesis. J Mol Med (Berl). 2003;81(10):600-612.

25. Wang M, Li G, Yin J, Lin T, Zhang J. Progranulin overexpression predicts overall survival in patients with glioblastoma. Med Oncol. 2012;29(4):2423-2431.

26. Zhang H, Serrero G. Inhibition of tumorigenicity of the teratoma PC cell line by transfection with antisense cDNA for PC cell-derived growth factor (PCDGF, epithelin/granulin precursor). Proc Natl Acad Sci U S A. 1998;95(24):14202-14207.

27. Lu R, Serrero G. Inhibition of PC cell-derived growth factor (PCDGF, epithelin/granulin precursor) expression by antisense PCDGF cDNA transfection inhibits tumorigenicity of the human breast carcinoma cell line MDA-MB-468. Proc Natl Acad Sci U S A. 2000;97(8): 3993-3998.

28. He Z, Ismail A, Kriazhev L, Sadvakassova G, Bateman A. Progranulin (PC-cell-derived growth factor/acrogranin) regulates invasion and cell survival. Cancer Res. 2002;62(19):5590-5596.

29. Lovat F, Bitto A, Xu SQ, et al. Proepithelin is an autocrine growth factor for bladder cancer. Carcinogenesis. 2009;30(5):861-868.

30. Tangkeangsirisin W, Serrero G. PC cell-derived growth factor (PCDGF/GP88, progranulin) stimulates migration, invasiveness and VEGF expression in breast cancer cells. Carcinogenesis. 2004;25(9): 1587-1592.

31. Han JJ, Yu M, Houston N, Steinberg SM, Kohn EC. Progranulin is a potential prognostic biomarker in advanced epithelial ovarian cancers. Gynecol Oncol. 2011;120(1):5-10.

32. Frampton G, Ueno Y, Quinn M, et al. The novel growth factor, progranulin, stimulates mouse cholangiocyte proliferation via sirtuin1-mediated inactivation of FOXO1. Am J Physiol Gastrointest Liver Physiol. 2012;303(11):G1202-G1211.
33. Yothaisong $\mathrm{S}$, Dokduang $\mathrm{H}$, Techasen $\mathrm{A}$, et al. Increased activation of $\mathrm{PI} 3 \mathrm{~K} / \mathrm{AKT}$ signaling pathway is associated with cholangiocarcinoma metastasis and PI3K/mTOR inhibition presents a possible therapeutic strategy. Tumour Biol. 2013;34(6):3637-3648.

34. Dokduang H, Juntana S, Techasen A, et al. Survey of activated kinase proteins reveals potential targets for cholangiocarcinoma treatment. Tumour Biol. 2013;34(6):3519-3528.

35. Liu P, Cheng H, Roberts TM, Zhao JJ. Targeting the phosphoinositide 3-kinase pathway in cancer. Nat Rev Drug Discov. 2009;8(8): 627-644.

36. Son H, Moon A. Epithelial-mesenchymal transition and cell invasion. Toxicol Res. 2010;26(4):245-252.

37. Techasen A, Namwat N, Loilome W, et al. Tumor necrosis factor-alpha (TNF-alpha) stimulates the epithelial-mesenchymal transition regulator Snail in cholangiocarcinoma. Med Oncol. 2012;29(5):3083-3091.

38. Techasen A, Namwat N, Loilome W, et al. Tumor necrosis factor-alpha modulates epithelial mesenchymal transition mediators ZEB2 and S100A4 to promote cholangiocarcinoma progression. J Hepatobiliary Pancreat Sci. 2014;21(9):703-711.

39. Duangkumpha K, Techasen A, Loilome W, et al. BMP-7 blocks the effects of TGF-beta-induced EMT in cholangiocarcinoma. Tumour Biol. 2014; 35(10):9667-9676.

40. Namwat N, Puetkasichonpasutha J, Loilome W, et al. Downregulation of reversion-inducing-cysteine-rich protein with Kazal motifs (RECK) is associated with enhanced expression of matrix metalloproteinases and cholangiocarcinoma metastases. J Gastroenterol. 2011; 46(5):664-675.
OncoTargets and Therapy

\section{Publish your work in this journal}

OncoTargets and Therapy is an international, peer-reviewed, open access journal focusing on the pathological basis of all cancers, potential targets for therapy and treatment protocols employed to improve the management of cancer patients. The journal also focuses on the impact of management programs and new therapeutic agents and protocols on

\section{Dovepress}

patient perspectives such as quality of life, adherence and satisfaction The manuscript management system is completely online and includes a very quick and fair peer-review system, which is all easy to use. Visit http://www.dovepress.com/testimonials.php to read real quotes from published authors. 